\title{
EMPODERAMENTO DA MULHER-DAMA? CORPOS DESEJANTES NA DANÇA DE SALÃO
}

\section{¿EMPODERAMIENTO DE LA MUJER-DAMA? CUERPOS DESEANTES EN EL BAILE DE SALÓN}

\author{
Carolina Polezi ${ }^{1}$ \\ Debora Reis Pacheco ${ }^{2}$
}

\begin{abstract}
Resumo: Este trabalho parte dos discursos de verdades produzidos na dança de salão sobre a mulher que assume o papel de dama problematizando as tentativas de escapes na contemporaneidade. No âmbito da dança de salão os papéis de homens e mulheres são claramente divididos a partir de uma perspectiva heteronormativa. Deste modo debate-se a ideia de mulher-dama carregada de elementos que definem um modo de ser na sociedade e na dança, bem como os movimentos que tentam desconstruir esses olhares a partir do empoderamento feminino, mas que são capturados pela máquina social mantendo os mesmos lugares de homens e mulheres, só que através de outra roupagem. Inicialmente apresenta-se uma breve contextualização da Dança de Salão. Posteriormente, a partir de um levantamento em livros e texto que circulam em sites, blogs e redes sociais visitados por dançarinos, apresenta-se uma análise principalmente sobre a perspectiva Deleuze Guattariana.
\end{abstract}

Palavras-chave: Máquinas Desejantes; dança de salão; gênero.

Resumen: Este trabajo empieza por los discursos de verdad producidos por el baile de salón acerca de la mujer-dama, problematizando los intentos de fuga en los tiempos contemporáneos. En la esfera del baile de salón, los roles de hombres y mujeres están claramente divididos desde una perspectiva heteronormativa. De esta manera, traemos a una mujer-dama cargada de elementos que definen una forma de estar en la sociedad y en la danza, así como los movimientos que intentan deconstruir esta mirada desde el empoderamiento de las mujeres, pero que son capturados por máquinas sociales que mantienen los mismos lugares de los hombres. y mujeres, pero con una apariencia diferente. Para eso, realizamos una encuesta sobre libros y textos que circulan en sitios web, blogs y redes sociales visitados por bailarines, dichos materiales fueron analizados desde la perspectiva de Deleuze Guattariana.

Palabras clave: Maquinas Deseantes; bailes de salón; género.

\section{Disciplinarização e civilidade nos salões de baile}

A dança de salão carrega consigo muitas simbologias que se manifestam em forma de relações sociais. As pistas de baile são um recorte da sociedade em que é possível compreender a dança de salão como produtora das estruturas sociais de poder, mas também a dança é produzida pela sociedade.

Desde o seu início, nos bailes de corte do século XV, a dança de salão foi uma importante ferramenta para disciplinar os corpos. Nesse período em que os Estados-Nações surgiam e o conceito ocidental de civilidade era empregado para justificar as grandes navegações, o domínio das populações ameríndias e a escravidão das pessoas africanas, se demarcar como um grupo civilizado, era uma importante maneira de estar dentro de um grupo de poder.

\footnotetext{
${ }^{1}$ Faculdade de Educação - Unicamp.E-mail: contato@ carolinapolezi.com.br.

${ }^{2}$ Universidade Federal de Mato Grosso do Sul - UFMS/PPGEduMat. E-mail: debora.rpacheco@gmail.com.
} 
Nos bailes de corte dos séculos XV ao XVIII, saber dançar era uma condição da vida social, não porque haveria grande prazer no movimento, mas porque através dos ensinamentos de dança, o sujeito adquiria o decoro corporal exigido para a vida em sociedade já que todos os professores de dança também eram mestres de etiqueta e boas maneiras. Além do mais, saber dançar permitia ao mestre de cerimônias formar os pares que pudessem ter interesses econômicos em juntar as fortunas através de casamentos arranjados.

A arte, nesse momento é entendida como uma técnica que vai produzir, moldar algo, a arte é um artifício e não tem uma concepção estética e expressiva como a compreendemos hoje. Sendo assim, o corpo deve ser moldado e produzido a partir da arte para a produção dos passos de dança. No manual de etiqueta e boas maneiras $O$ cortesão de 1528 escrito por Baldassare Castiglione, um conde italiano, o autor vai falar sobre a importância do decoro para a distinção dos sujeitos e explica que os gestos devem ser moderados, simples e modestos.

Nesse sentido a arte de dançar deve gerar o que ele define como sprezzatura, que é ocultar um trabalho técnico árduo para que ele pareça ser realizado sem esforço, afinal o trabalho não é uma atividade da nobreza, mas sim da plebe. A bailarina tem por objetivo mostrar que a sua dança é simples e sublime, que seus trejeitos e gestos não foram condicionados por anos de treino e prática, mas sim é algo natural e simples. A graça é o resultado da mobilização de todos esses recursos.

A arte (enquanto técnica), a sprezzatura e a graça como resultado vão também distinguir quais os gestos ideias para homens e mulheres. Aos homens as características de razão, força e controle serão relacionadas, enquanto às mulheres a qualidade de empatia, leveza e beleza serão cobradas. Todas as aulas de etiqueta e dança serão ferramentas para condicionar, a partir de muito trabalho técnico, que corpos de homens e mulheres respondam de maneiras diferentes, mas sempre escondendo o trabalho necessário para a disciplinarização. Em seu lugar, os corpos devem se movimentar de maneira a manifestar apenas a graça.

As maneiras cortesãs superficiais eram como um verniz aparentemente bonito usado para esconder as relações de poder que se disputava nos ambientes de baile de corte. Os homens se portavam com uma cortesia elegante e ensaiada. As danças de salão eram uma forma de cortejo entre homens e mulheres e, sobretudo, uma ferramenta para proporcionar encontros por conveniência social entre as famílias nobres.

Essa ética é baseada numa relação cavalheiresco-amorosa em que se coloca a mulher em uma posição etérea de forma a nunca ser alcançada, tornando-a um objeto de desejo inatingível e irreal. Essa relação tira a humanidade, exigindo que seus gestos a colocando apática e passiva perante ao pretendente e toda a sociedade cortês. Silveira e Majerowicz (2018) acreditam que a objetificação do corpo feminino por detrás desta apologia, priva a mulher de atuar na sociedade - ou na dança - e reduz seu papel ao âmbito privado, relegando a mulher apenas às atividades domésticas.

Para Georges Duby (1997), o cortejo cavalheiresco pode ser entendido como uma disputa de valores viris entre homens, em que o seu grande prêmio é o corpo da mulher, que precisa se colocar "ausente de desejo e que deve ceder ao homem que desempenha melhor o papel do cavalheiro - forte, corajoso, soberano, dominador e responsável pela mulher: frágil, doce, submissa, sensual e obediente" (SILVEIRA; MAJEROWICZ, 2018). A cortesia requer que a mulher se mostre fria.

É uma codificação das condutas de amar e se relacionar que coloca uma organização social a partir das relações de poder e de desejo entre homens e mulheres. No Tratado de Capelão, um manual de como o amor cortês deve ser, normas de como as mulheres devem agir perante o homem e da mesma forma manuais de conduta foram amplamente difundidos no Renascimento ensinando o decoro e a dança nos ambientes sociais dos salões de baile. 


\section{Condução e condutas dos salões e da sociedade}

As condutas de homens e mulheres na dança de salão vão reger os modos de conduzir o corpo. Nas quadrilhas e contradanças os homens já tinham a responsabilidade de levar a mulher a fazer os movimentos, mesmo que essa dança fosse realizada a partir de uma coreografia.

Ao homem era permitido a ação de tirar um mulher-dama para dançar e deveria fazê-lo com a autorização do parente responsável (normalmente um pai, irmão ou marido, todos homens), enquanto a ela cabia apenas a espera. Ele deveria conduzir a sua dama até a pista de dança e o toque entre os dançarinos era cuidadoso e distante para que não causasse o rubor daqueles que dançam. Era fundamental que homens e mulheres estivessem enluvados para que as peles dos dedos não se tocassem. Ao final o homem-cavalheiro deveria retornar a mulherdama a posição onde a encontrou e agradecer a ela e ao homem que autorizou a dança. A historiadora Mary Del Priore (2016) "na dança de salão, notadamente na valsa, confirmava-se outra regra social: era o homem quem, no privado ou no público, conduzia a mulher." (p. 254).

Com o advento da valsa, primeira dança de par entrelaçado surgida na primeira metade do século XIX, a técnica da condução se aprofunda e sofistica, tornando o homem responsável pelo planejamento, construção e condução de toda a dança e do corpo da mulher, que deveria se deixar levar de maneira obediente, "la mujer se deberá entregar como una sonámbula, para poder sentir y acompanãr mejor a su hombre" (NAU-KLAPWIJK, 2006, p. 169 apud SILVEIRA; DANTAS, 2014, p. 7).

As posições de homem-cavalheiro e mulher-dama são justificadas pelos atributos naturalizados dos gêneros como as características masculinas de "segurança, determinação, objetividade, habilidade e domínio técnico" (GAIO; FIORANTI; COAN, 2009, p. 48) são tidas como mais apropriadas ao melhor desempenho da condução, enquanto à mulher cabe ser conduzida por suas características de "sensibilidade, empatia, criatividade e emotividade" (GAIO; FIORANTI; COAN, 2009, p. 48).

Os papéis de dama-conduzida e homem-condutor se estabelecem e são viabilizados pela técnica da condução, que é a ação de o homem levar a mulher a realizar seguidos movimentos, de forma a construir a dança (NOGUEIRA, 2009).

Desde o surgimento da valsa até atualmente, a condução continua sendo a espinha dorsal da dança de salão e essa técnica ainda determina os papéis a que homens e mulheres devem corresponder. Várias são os exemplos da reprodução dessa ideia como a de Bettina Ried (2003) que reforça a mesma ideia de diferença de papéis de acordo com o gênero e seus supostos caráteres instintivos: "O conduzir do cavalheiro exige segurança, determinação, objetividade, habilidade e domínio técnico, enquanto que o seguir da dama, por sua vez, requer sensibilidade, empatia, criatividade e emotividade" (p. 37).

Como afirma Bettina Ried (2003) "o conduzir do cavalheiro exige segurança, determinação, objetividade, habilidade e domínio técnico, enquanto que o seguir da dama, por sua vez, requer sensibilidade, empatia, criatividade e emotividade" (p. 37).

Bourdieu (1998) nos lembra que ao longo da história as diferenças anatômicas entre os órgãos sexuais de homens e mulheres são usadas como justificada para "a diferença socialmente construída entre os gêneros" (BOURDIEU, 2007, p. 20), refletindo, assim, nos modos de relacionar, mover, vestir, desejar, dentre outros, o que é possível perceber nos papéis que cabem a homens e mulheres dentro da dança de salão.

A lógica binária nos salões de baile é uma constante que é possível observar das ideias insistentemente de dualismo homem-mulher, condutor-conduzido, razão-sensibilidade, forçaleveza. Tal lógica binária se apresenta no plano do visível, como destacam Polezi e Martins (2019), ao colocar o homem como condutor por suas características de proteção, dominação, 
força e vigor, enquanto a mulher é designada para o papel de conduzida por seus aspectos de submissa, pequena e sensível e, assim, assegurar o equilíbrio do casal (SILVEIRA, 2012). E também se apresenta no plano do invisível que limita mulheres e homens a ocuparem um único lugar possível em que o homem-condutor executa a criação, expressão e musicalidade da dança, enquanto à mulher-conduzida cabe apenas responder aos estímulos, com reduzidas chances de manifestar sua expressão artística.

[... A] dança pode ser entendida como uma dentre as várias instâncias culturais que "fabricam" homens e mulheres de determinados tipos, é preciso, a partir daí, analisarmos as formas pelas quais as identidades de gênero são construídas, para pensarmos nas diferentes possibilidades ou modos de subjetivação e singularização vivenciados por homens e mulheres nesse contexto (ANDREOLI, 2010, p. 116).

A dança de salão é uma das instituições relacionadas com os processos sociais e históricos que constituem o corpo, poucas características naturais ainda restam, o corpo é, antes de tudo, um produto da subjetivação. "Pois o corpo é, ele próprio um processo. Resultado provisório das convergências entre técnica e sociedade, sentimentos e objetos, ele pertence menos à natureza do que à história" (SANT' ANNA, 1995, p. 12).

\section{Empoderamento feminino e as máquinas desejantes}

Tais estereótipos da mulher-dama e do homem-cavalheiro visibilizados pelas tradicionais técnicas de condução veem sendo questionados na contemporaneidade com as discussões sobre empoderamento feminino na sociedade. É possível encontrar uma série de aulas, workshops e outros produtos que buscam promover a autonomia da mulher, na tentativa de quebrar os hábitos construídos.

No entanto, não podemos deixar de questionar que muitas das tentativas de escape dos papeis estabelecidos de mulher-dama e homem-cavalheiro podem ser cooptados pela engrenagem socialcapitalista que vivemos hoje, esvaziando discursos para torna-los mercadoria.

Palavras como "empoderamento" vem ganhando muitos espaços nos meios sociais, mas se faz necessários analisar como elas se movimentam e o quanto realmente conseguem fraturar um funcionamento social-capitalista. Por meio dos espaços da Dança de Salão tais análises podem ser potentes, já que as discussões entre mulher-dama e homem-cavalheiro são explicitadas nas técnicas de condução.

Para tanto nos debruçamos a analisar cuidadosamente algumas propostas de empoderamento feminino que, mesmo que a primeira vista pareçam promover relações mais igualitárias entre homens e mulheres com maior autonomia do corpo feminino, quando observamos os discursos é possível perceber que algumas palavras escapam reafirmando o estereótipo dessa mulher-dama.

Somos mulheres independentes na vida e, muitas das vezes, levamos essa postura para o salão. Não que a iniciativa feminina seja algo indesejável no samba de gafieira, mas temos que ter o cuidado para não ficarmos ansiosas e não anteciparmos a condução indicada. Os enfeites devem ser executados "entre" os movimentos indicados, sem que estejamos apoiadas em nossos parceiros, sem tirá-los do eixo com muito cuidado e leveza. (AQUINO, 2016, p. 85, grifo nosso)

$\mathrm{Na}$ citação apresentada é possível observar uma movimentação das mulheres em construir outras formas de ser mulher-dama e de se expressar na dança. No entanto, Deleuze e Guattari 
(2010b) nos lembram que somos parte de um aparelho de estado e somos cooptados pelas máquinas sociais à todo momento. No trecho acima, ainda que exista um desejo de independência, nota-se um deslocamento quando as palavras "cuidado" e "leveza" se fazem presentes. A conjunção adversativa "mas" anula o desejo de independência e autonomia recolocando os movimentos da mulher-dama nos poucos espaços permitidos pelo homem-cavalheiro.

O desejo pela autonomia atende à tendência desse novo tempo, mas não rompe com as características da mulher-dama que ainda depende do que é cedido pelo homem-cavalheiro. Trata-se então de um desejo fabricado pelas máquinas sociais, ou pelo aparelho de estado, e não do desejo na perspectiva de Deleuze e Guattari (2010b).

Uma outra professora, dos materiais analisados, propõe quatro estágios definindo os papéis de damas e cavalheiros. Nos dois primeiros estágios seguem-se os mesmos estereótipos de homem-condutor-cavalheiro e mulher-conduzida-dama, com alguns pequenos refinamentos. A partir do terceiro estágio há uma tentativa de empoderar a dama, mas os recalques ainda são latentes, nele a mulher-dama é incentivada a usar do "silêncio de condução" para realizar seus "enfeites", mas é o homem-cavalheiro que "gera mais tempo para os caminhos e enfeites da dama" (SANTOS, 2016, p. 108). Já no quarto estágio, em que a mulher estaria no cenário mais empoderado, ela ainda deve "adornar" seus movimentos "pedindo mais tempo" (SANTOS, 2016, p. 110) ao seu homem-cavalheiro.

Nestas situações novamente é possível perceber as fragilidades que escapa quando os desejos são fabricados socialmente, já que as mulheres-damas "definidas" nos estágios precisam pedir permissão para ampliarem suas possibilidades de movimentação, ou seja, ainda está no homem-cavalheiro a decisão e controle dos movimentos dancísticos. As tentativas de escapar de uma identidade de mulher-dama submissa ainda estão amarradas, o que nos faz perceber a complexidade dos movimentos de escape em relação ao aparelho de estado vigente.

Há alguns cursos formadores de profissionais da dança de salão que buscam construir o empoderamento da mulher também enquanto professoras e não somente como dançarina. A primeira vista tais iniciativas poderiam ser vistas como máquinas desejantes na perspectiva deluze-guattariana, que produz cortes e cria linhas de fuga, mas novamente olhando mais de perto vemos os desejos sendo recapturados para manter a máquina azeitada.

O Congresso Online MIND ${ }^{74}$ (2019) - Mulheres Influenciadoras na Dança que teria como objetivo construir linhas de fuga através da mobilização de mulheres acaba reproduzindo os mesmos discursos machistas e heteronormativos que disciplina o corpo feminino. Na postagem em redes sociais divulgando uma das palestrantes do curso é possível observar a descrição: "Condução, como me tornar uma dama mais 'obediente'?" (grifo nosso). Nesse módulo as professoras debateriam através da análise comportamental qual o corpo da dama e como esse corpo pode se tornar obediente.

A carga que o termo dama carrega já foi amplamente debatido nesse artigo, ilustrando com essa palavra traz uma bagagem histórica que remonta a disciplinarização iniciada com a criação do Estado-Nação. A palavra obediente, por mais que esteja acompanhada por aspas, reforça o papel subjugado e controlado a que as mulheres e, portanto, as damas, foram colocadas ao longo da história. Tudo isso endossado por uma roupagem científica de uma analista comportamental, ou seja, alguém que teria formação para falar sobre o tema de maneira acadêmica. Deleuze e Guattari (2010b) nos chamam a atenção para a fabricação do desejo que as máquinas sociais produzem nos corpos desejantes, não vamos esquecer que o patriarcado e o capitalismo dividem uma mesma lógica de opressão e exploração de mulheres. A dança de

\footnotetext{
${ }^{74}$ Fonte: https://www.instagram.com/p/B42WP2sFjym/. Acesso em: 01 fev. 2020.
} 
salão, como uma máquina social, acopla e organiza corpos, cooptando seus cortes para que sejam eficientes para a manutenção da própria máquina social.

Os incômodos das professoras sobre os papéis estabelecidos tradicionalmente reverberam também na fala de professores-homens ao serem provocados na contemporaneidade: "Não sou machista, muito pelo contrário, adoro conduzir e sempre dou espaço para a dama se expressar, brilhar e me ajudar na minha musicalidade e criatividade." (ARÔXA, 2017, grifo nosso). Nesta fala, embora haja a defesa da não construção de um machismo, o professor ainda é quem controla e "dá" espaço para a mulher-dama se expressar. Ainda é o homem-cavalheiro quem dá permissão para que as mulheres-damas possam "empoderar-se" ou ampliarem suas possibilidades na dança de salão.

A arte tem desejo de potência, ela é capaz de tornar o caos sensível, para Deleuze e Guattari (2010a) a arte é um "bloco de sensações, isto é, um composto de perceptos e afectos" (p. 193). Mas as técnicas e dispositivos de um aparelho de estado e todas suas máquinas sociais são cada vez mais eficiente e s sutis para captar tal desejo. Ou seja, aqueles que buscam, por meio da dança de salão, uma ferramenta de expressão e desejo, estão a todo tempo envolvidos nos jogos de captura.

Os alunos de dança de salão não conseguem imaginar a quantas normas os movimentos e os corpos estão sujeitos. Em especial as mulheres são constantemente subjetivadas para reproduzir um corpo considerado ideal e feminino. A professora Maristela Zamoner mostra o processo pela qual toda mulher deve passar e como a dança de salão pode ser uma ferramenta importante na construção da ideia de feminilidade. Em seu texto "O poder da metamorfose feminina na dança de salão" a autora narra como algumas mulheres chegam às aulas de dança de salão:

Quem já não notou uma lagarta esquisita entrando pela porta da sala de aula de dança de salão, com calças largas, camisetões, óculos, rabo de cavalo, mantendo-se quietinha por dias e saindo transformada um tempo depois? [...] Cria-se a coragem de encarar o espelho, descobrir as próprias ondulações debaixo do esconderijo protegido dos panos largos, que a cada dia, descascamse. Começa a dar-se nitidez às curvas sensuais e livres que tanto atraíram Niemeyer. No olhar de Álvares de Azevedo, curvas que gravam na roupa o "contorno eloquente". (ZAMONER, 2012, s.p.)

Nessa imagem construída pela autora em que ela compara uma mulher com o processo de transformação da lagarta em borboleta ela usa da ideia de que uma série de acessórios ou modos de se vestir, como as calças largas, o óculo e o rabo de cavalo estariam conectados a fase feia e não desejada da lagarta. E ela sinaliza que a dança de salão é a ferramenta de transformação da mulher-lagarta em mulher-borboleta. "A dança de salão é a chave que abre o baú de encantos e coragens, é a chave da liberdade de ser quem se é" (ZAMONER, 2012, s.p.).

Esse desejo de "ser quem se é" nos parece na verdade fabricado pela máquina social, em que apenas uma maneira de ser é aceitável, e certamente alguns vestuários, gestos, trejeitos e movimentos não são ideais para representar o que é ser mulher. Em contrapartida a autora segue.

E em algum momento, que mal sabemos precisar qual é, sai daquela porta a voluptuosidade dos cabelos sedosos, soltos à brisa, dos olhos brilhantes visíveis de longe, dos dentes mais brancos, da pele mais lisa, das lindas asas pintadas em saia, transbordando erotismo. Fica pronta para alçar voo, segura, vertendo na postura, nos movimentos exploradores de curvas e nas expressões, a mixagem da confiança com a nudez do êxtase. Esta metamorfose não se restringe à sala de aula ou ao salão. Inunda todos os meandros desta vida, a casa, o guarda-roupas, o chuveiro, as refeições, a atenção à saúde. Sem tratamento estético, há redução do cenho franzido e o desenfrear do sorriso que emoldura qualquer fala, fácil, 
provocativo, doce ou malicioso. Transforma as relações com outras pessoas e a produtividade profissional. Espanta o pó do estojo de maquiagem, acorda a paixão pelos saltos altos, pelas cores, justezas e brilhos, pelos frascos de perfumes. Cria a sede pelas novas descobertas. Devolve o sexo, para ser descoberto como se quer. E sempre há mais a desvendar nos mistérios ali enclausurados. (ZAMONER, 2012, s.p., grifo nosso)

A dança de salão, através das práticas, das técnicas e dos discursos vai subjetivando as mulheres a ocupar as mesmas posições de sempre só que agora disfarçadas de empoderamento. No texto acima algumas palavras em grifo vão construindo um desejo de imagem e estética feminina com cabelos sedosos, dentes brancos, pele lisa (em oposição a pele enrugada, a mulher velha) e curvas. Para tanto a mulher deve se paramentar de uma série de itens como saia, maquiagem, salto alto e perfumes. A estética os artigos utilizados para produzir o que socialmente é considerado uma mulher só será completo quando tais elementos afetarem também os gestos, movimentos e sentimentos delas, que devem se mostrar eróticas, provocativas, maliciosas e misteriosas, mas que ainda assim devem preservar a docilidade e postura tida como natural e inerente a mulher.

Essas produções ilustram o que a dança de salão ainda hoje defende sobre como deve ser uma mulher-dama. Outro exemplo está na fala da professora Sheila Aquino ao enfatizar que "ser uma boa dama não é saber milhões de passos, mas sim aprender a ser de fato uma 'parceira' de dança, embelezando com alegria, energia e leveza os passos indicados pelo cavalheiro." (2016, p. 98, grifo nosso). Ainda outro professor reforça estes papéis ao afirmar que "se o homem conduz, a mulher induz e seduz." (ARÔXA, 2017)

\section{Considerações finais}

As capturas pelas máquinas sociais sempre irão acontecer, nossos desejos são deslocados a todo momento por dispositivos cada vez mais articulados. Mas, ainda assim, é possível escapar. Analisar as tentativas frágeis de escapes nos dão elementos para que outras tentativas possam ser inventadas, para que os fluxos de desejo possam ser potencializados desviando dos processos de fabricação social

Afinal, somos máquinas desejantes.

Dentro da vida social o que nos oferecem é a imagem a qual devemos nos encaixar, suprimindo nossos desejos. Apesar dos esforços em escapar e criar um outro lugar de ocupação para a mulher-dama dentro da dança de salão, nota-se que essas mulheres, nos exemplos apresentados, continuam enredadas dentro dos estereótipos tradicionais de gênero que são refletidos na dança de salão.

Os discursos são muito fortes e sedutores, sendo difícil romper um ideário de mulher-dama e homem-cavalheiro. Assim, muitas dessas iniciativas sequer chegam a escapar-fissurar o aparelho de estado, mostrando que fraturar o sistema e o imaginário da mulher-dama é complexo e está sendo constantemente capturado para manutenção dos mesmos papéis na dança de salão.

Tais exemplos não impedem que outros modos de existir na Dança de Salão, e consequentemente fora dela, possam ser inventados. Seguimos nos sensibilizando com arte, na tentativa de operar como máquina desejante que somos. 


\section{Referências}

ANDREOLI, G. S. Dança, gênero e sexualidade: um olhar cultural. Revista Conjectura, Caxias do Sul, v. 15, n. 1, p. 107-118, jan.-abr. 2010.

AQUINO, Sheila. A dama no samba de gafieira. In: FILHO, Rubens Pantano, SUAYA, Alejandro "Turco", OLIVEIRA, Rodrigo de. Tango e samba: um encontro de duas culturas. Indaiatuba-SP: Gráfica e Editora Vitória, 2016. p. 83-88.

AROXA, Jaime. Oi gente, hoje é sobre condução. 2017. Disponível em: https://www.facebook.com/jaimearoxa/posts/1422534467777128. Acesso em: 12 fev. 2017.

BOURDIEU, Pierre. Conferência do prêmio Goffman: a dominação masculina revisitada. In: LINS, D. A dominação masculina revisitada. Campinas: Papirus, 1998, p. 11-27.

BOURDIEU, Pierre. Escritos de educação. Petrópolis: Editora Vozes, 2007.

CASTIGLIONE, Baldassare. O cortesão. Trad. Carlos Nilson Moulin Louzada. São Paulo: Martins Fontes, 1997.

DELEUZE, Gilles; GUATTARI, Felix. O que é a filosofia? 3. ed. São Paulo: Editora 34, 2010a.

DELEUZE, Gilles e GUATTARI, Félix. $O$ anti-Édipo: capitalismo e esquizofrenia. Trad. Luiz B. L. Orlandi. São Paulo: Editora 34, 2010 b.

DEL PRIORE, Mary. Histórias da gente brasileira: v. 2 - Império. São Paulo: Leya, 2016.

DUBY, Georges. Damas do século XII: a lembrança dos ancestrais. Trad. Maria Lúcia de Machado. São Paulo: Companhia das Letras, 1997.

GAIO, R.; FIORANTE, F.; COAN, A. B. Corpo e movimento na dança de salão: discussão sobre gênero. Coleção Pesquisa em Educação Física, v. 8, n. 2, p. 45-52, 2009.

MAJEROWICZ, Ilana Taya I.; SILVEIRA, Paola de Vasconcelos. Cavalheirismo não é gentileza: elucidações sexistas no pensar contemporâneo da dança de salão. $41^{\circ}$ CONGRESSO BRASILEIRO DE CIÊNCIAS DA COMUNICAÇÃO. Anais Intercom: Sociedade Brasileira de Estudos Interdisciplinares da Comunicação. Joinville, v. 1, n. 1, p. 1-13, set. 2018.

NOGUEIRA, K. Quem conduz na dança? uma nova realidade para o século XXI. Dança de Salão, 2009. Disponível em: http://dancasalaojoinville.com/blog/2009/10/conducao-homemxmulher. Acesso em: 02 jul. 2016.

POLEZI, Carolina; MARTINS, Anderson Luis Barbosa. Condução e contracondução na dança de salão. Periódico Horizontes, USF, Itatiba, v. 37, p. 1-14, 2019.

RIED, Bettina. Fundamentos de dança de salão. Londrina: Midiograf, 2003. 
SANT'ANNA, Denise Bernuzzi. Cuidados de si e embelezamento feminino: fragmentos para uma história do corpo no Brasil. In: SANT'ANNA, D. B. (Org.). Política do corpo. São Paulo: Estação Liberdade, 1995. p. 121-139.

SANTOS, Sheila. Samba e tango: uma visão contemporânea das relações na dança a dois. In: FILHO, Rubens Pantano, SUAYA, Alejandro "Turco", OLIVEIRA, Rodrigo de. Tango e samba: um encontro de duas culturas. Indaiatuba-SP: Gráfica e Editora Vitória, 2016. p. 101-114.

SILVEIRA, Paola de Vasconcelos; DANTAS, Mônica. Diálogos de um ser a dois: uma perspectiva para dançar o tango para além da condução. In: CONGRESSO NACIONAL DE PESQUISADORES EM DANÇA, 3., 2014. Anais... setembro, p. 1-8, 2014.

SILVEIRA, Paola de Vasconcelos. Diálogos de um ser a dois: uma perspectiva para dançar tango. 2012, 40f. TCC (Dança) - Universidade Federal do Rio Grande do Sul, Porto Alegre, 2012.

ZAMONER, Maristela. O poder da metamorfose feminina na dança de salão. Dança em Pauta, Curitiba, 2012. Disponível em: http://site.dancaempauta.com.br/o-poder-da-metamorfosefeminina-na-danca-de-salao/. Acesso em: 02 mai. 2020. 